\title{
INVESTIGACIÓN/RESEARCH
}

\section{VALORACIÓN POLÍTICO CRIMINAL DEL CODIGO PENAL DE 1995}

\author{
Fernando Santa Cecilia García: Universidad Complutense de Madrid (España).
}

\section{El código penal de 1995}

Los fracasados intentos de elaboración y promulgación de un Código Penal de nueva planta que respondiera a los principios democráticos y constitucionales, a partir de la transición política en España, motivaron que el legislador tuviera que optar por el sistema de reformas parciales ${ }^{1}$. El Consejo de Ministros de 22 de julio de 1994 aprueba un proyecto de Código Penal que fue enviado a las Cortes Generales el 26 de septiembre de 1994, por el entonces Ministro Juan Alberto Belloch. El proyecto fue aprobado por el Pleno del Congreso de los Diputados, en sesión plenaria, el 8 de noviembre de 1995², promulgándose por Ley Orgánica 10/1995, de 23 de noviembre, del Código Penal ${ }^{3}$. Con este importante acontecimiento legislativo para la sociedad española culminan los anteriores intentos de los diferentes proyectos, adaptándose el Código Penal a los valores y principios de una sociedad moderna ${ }^{4}$.

Los diferentes proyectos de reforma del Código Penal fueron: el llamado proyecto de Ley Orgánica del Código Penal de 1980, la propuesta de anteproyecto de Código Penal de 1983 y el proyecto de Código Penal de 1992, cuyo borrador de anteproyecto de la parte general fue de 1990. Vid. sobre la materia, LASSO GAITE, JF., en Crónica de la Codificación Española, 5, Codificación Penal, vol. I., Ministerio de Justicia, Secretaría General Técnica, Centro de Publicaciones, Madrid, 1970, págs. 910 a 914 y 918 y ss.; RODRÍGUEZ DEVESA, JMª.SERRANO GÓMEZ, A., en Derecho Penal Español PG., 18 ${ }^{\mathrm{a}}$ edic., revisada y puesta al día. Edit. Dikynson, Madrid, 1995, págs. 145 a 153; GARCÍA PABLOS DE MOLINA, A., «Proyecto de Código Penal de 1992. Parte General (Teoría jurídica del delito)», en La Reforma del Código Penal, Revista ICADE, Madrid, 1993, núm. 29, págs. 57 y ss.

2 Advierte la doctrina que el proyecto, se aprobó sin «los antecedentes necesarios para pronunciarse» según exige el art. 88 de la Constitución, por lo que el proyecto «no cumple con los requisitos que exige el Texto Constitucional», vid. SERRANO GÓMEZ, A., «El proyecto de Código Penal de 1994 y las previsiones del art. 88 de la Constitución», en Revista de Derecho Penal y Criminología, núm. 4, Madrid 1994, págs. 867 y ss.; y que «no intervino la Sección de Derecho Penal de la Comisión General de Codificación pese a ser preceptivo», vid. BUENO ARÚS, F., «La teoría de la Ley penal en el proyecto de Código Penal Español de 26 de septiembre de 1994», en Actualidad Penal, nº 16, Madrid, 1995; GRACIA MARTÍN, L., «Política criminal y dogmática jurídico penal del proceso de reforma penal en España», en Actualidad Penal no 17 y 18, 1994; MANZANARES SAMANIEGO, JL., «Comentarios a la parte general del proyecto de Ley Orgánica del Código Penal», en Revista de Derecho Penal y Criminología, núm. 2, Madrid, 1992, págs. 375 y ss.

3 Publicado en el BOE. núm. 281 de 24 de noviembre de 1995.

4 Vid. LÓPEZ GARRIDO, D./GARCÍA ARAN, M., en El Código Penal de 1995 y la voluntad del legislador. Comentario al texto y al debate parlamentario. Madrid, 1996, págs. 25 y ss.; Sobre las

Recibido: 15/07/1996---Aceptado: 16/08/1996---Publicado: 28/11/1996 


\section{$\underline{\text { Principios informadores. Estructura y características }}$}

El Código Penal de 1995 está inspirado en los principios constitucionales y político criminales del hecho, bien jurídico, intervención mínima, legalidad, culpabilidad, proporcionalidad y resocialización. Además, se basa en los anteriores proyectos, anteproyectos, borradores y propuestas prelegislativas que a partir de 1980 se han ido sucediendo, en especial las discusiones parlamentarias del Proyecto de 1992, enmiendas presentadas al mismo en el Congreso, informe de la ponencia, dictamen de la Comisión, del Consejo General del Poder Judicial, jurisprudencia y doctrina científica ${ }^{5}$.

La estructura del Código Penal de 1995 se integra por un total de 639 artículos, distribuidos en tres libros, precedidos de un Título preliminar, apartándose, pues, de los modelos anteriores ${ }^{6}$. El Título preliminar trata «De las garantías penales y de la aplicación de la Ley penal»; Libro I: «Disposiciones generales sobre los delitos y las faltas, las personas responsables, las penas, medidas de seguridad y demás consecuencias de la infracción penal»; Libro II: «Delitos y sus penas»; Libro III: «Faltas y sus penas». A su vez, el articulado del Código se distribuye en títulos, capítulos y secciones. Contiene tres disposiciones adicionales, doce transitorias, una disposición derogatoria y siete disposiciones finales.

De entre las características más significativas que presenta el Código Penal, destacamos las siguientes: En el Título preliminar se recogen los principios elaborados por la jurisprudencia y doctrina para la interpretación de las leyes garantistas con criterios relevantes para la aplicación de las penas. El Derecho Penal que se contiene es un Derecho Penal del hecho y no de autor, por lo que al delincuente se le castigará por lo que haga y no por la concreta personalidad que pueda tener (arts. 1 y 10 C.P. en relación con el art. 25 C.E.) $)^{7}$. Se reconoce los principios de legalidad (no solo de delitos y penas, sino de medidas de seguridad), consagrado en las garantías criminal, penal, jurisdiccional y de ejecución (arts. 1, 2, 3, 4, 10 y 12 C.P. en relación con los arts. 1, 9.3, 24, 25,1 y 117 C.E.). El art. 2.1 recoge la prohibición de retroactividad extendiéndose ahora a las medidas de seguridad, incorporando un trámite preceptivo pero no vinculante de audiencia del reo para los supuestos «de duda sobre la determinación de la ley más favorable». Otra novedad, es la previsión contenida en el apartado 2, art. 2, referente a las leyes temporales, pues los hechos cometidos bajo su vigencia «serán juzgados, sin

objeciones al nuevo Código Penal de 1995, GIMBERNAT ORDEIG, E., «Prólogo a la segunda edición»,

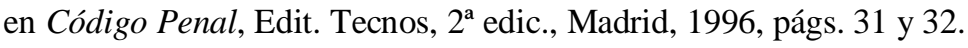

5 Vid. Exposición de motivos de la LO. 10/1995, de 23 de noviembre, del Código Penal.

6 Salvo las excepciones de los Códigos Penales de 1822 y 1928 ningún otro Código Penal español tuvo títulos preliminares.

7 Vid. ANTÓN ONECA, J., para quien «el hombre no delinque en cuanto es, sino en cuanto obra», en Derecho Penal, $2^{\mathrm{a}}$ edic., anotada y puesta al día por José Julián Hernández Guijarro y Luis Beneytez Merino, Edit. Akal, Madrid, 1986, pág. 182. 
embargo, conforme a ella, salvo que se disponga expresamente lo contrario». Se recoge la prohibición de la analogía (art. 4.1 C.P.), sin necesidad de acudir al Código Civil (art. 4.2 CC.). El art. 4, apartados 2 y 3, especifican las atribuciones que corresponden al órgano jurisdiccional que puede hacer uso de acuerdo con dicho precepto, cuando «tenga conocimiento de alguna acción u omisión que sin estar penada por la ley estima digna de represión, se abstendrá de todo procedimiento sobre ella y expondrá al Gobierno las razones que le asistan para creer que debiera ser objeto de sanción penal», o de acudir al Gobierno «exponiendo lo conveniente sobre la derogación o modificación del precepto o la concesión de indulto, sin perjuicio de ejecutar desde luego la sentencia...», con la particularidad en este segundo caso, de que la solicitud de indulto pueda producir efectos suspensivos de la ejecución de la pena «en tanto no se resuelva sobre la petición formulada» (art. 4.4), pudiendo potestativamente, aunque ex oficio, «el Juez o Tribunal suspender la ejecución de la pena mientras no se resuelva sobre el indulto, de ser ejecutada la sentencia, la finalidad de éste pudiera resultar ilusoria» (art. 4.4, p. segundo). El art. 5 recoge el principio de culpabilidad al decir «No hay pena sin dolo o imprudencia», apartándose de toda idea de responsabilidad objetiva basada en el resultado ${ }^{8}$. Con relación a las medidas de seguridad, el Código prescinde de las llamadas predelictuales y el art. 6 contiene una doble declaración, por un lado que dichas medidas «se fundamentan en la peligrosidad criminal del sujeto... exteriorizada en la comisión de un hecho previsto como delito» (art. 6.1), lo que confirma a su vez el art. 95.1 ${ }^{\text {a }}$, y por otro «las medidas no pueden resultar ni más gravosas ni de mayor duración que la pena abstractamente aplicable ... ni exceder el límite de lo necesario para prevenir la peligrosidad del autor». Novedad, también, la determinación del momento de la comisión de la infracción penal (art. 7). El Código resuelve los concursos de leyes acogiendo en su art. 8 las cuatro reglas tradicionalmente descritas por la doctrina científica: especialidad, subsidiariedad, consunción y alternatividad; tales reglas dejan a salvo los problemas del concurso ideal y del concurso real de delitos en virtud de la remisión expresa a los artículos 73 a 77 del propio Código. Finalmente, el art. 9 establece la regla de supletoriedad respecto de las leyes penales especiales, y el rango, en todo caso, prioritario de las disposiciones contenidas en el Título preliminar de este Código. Se echa en falta una regulación del ámbito espacial de la ley penal que evitaría tener que acudir a leyes complementarias, como la Ley Orgánica del Poder Judicial (art. 23), para determinar la aplicación del principio de territorialidad y sus excepciones.

El Libro Primero aporta importantes innovaciones: introduce una cláusula general incompatible con el principio de mínima intervención, que permite fundamentar la responsabilidad criminal en comisión por omisión (art. 11), hubiera sido más respetuoso, con dicho principio, acudir a otras opciones político criminales como la regulación uti singuli en la parte especial de los supuestos de omisión impropia

8 El Código suprime la fórmula «cuando la pena venga determinada por la producción de un ulterior resultado más grave, sólo se responderá de éste si se hubiere causado, por culpa», consecuentemente desaparecen los delitos cualificados por el resultado y la circunstancia atenuante de preterintencionalidad. Por innecesario desaparece la alusión al caso fortuito. 
merecedores de pena ${ }^{9}$; en cambio el legislador ha utilizado la fórmula de incriminación cerrada crimena culposa abandonando la cláusula general crimen culpae para la regulación del delito imprudente, sin duda más conforme con el principio de mínima intervención y respetuoso con el de legalidad (art. 11 en relación con los arts. 5 y 10), este sistema de incriminación selectiva (uti singuli) deviene excepcional, lo que obliga, en la parte especial, a determinar las figuras concretas objeto de incriminación ${ }^{10}$. En línea con el principio de intervención mínima, la incriminación de los actos preparatorios (proposición, provocación y conspiración) sólo se castigarán en el casos especialmente previstos en la ley (arts. 17 y 18.1), por lo que será, en la parte especial del Derecho Penal, donde deban penarse uti singuli estos actos; «la apología sólo será delictiva como forma de provocación y si por su naturaleza y circunstancias constituye una incitación directa a cometer un delito» (art. 18, p. $2^{\circ}$ ). La definición de delito (art. 10), régimen del error y su relevancia penal (art. 14) no implican modificaciones sustanciales. El Código opta por una clasificación tripartita de las infracciones penales, distinguiendo las graves, menos graves y leves, de acuerdo, a su vez, con la mayor o menor gravedad de las penas (art. 13.1.2.3. y 33) y resuelve «cuando la pena, por su extensión, pueda incluirse a la vez entre las mencionadas en los dos primeros números de este artículo, el delito se considerará, en todo caso, como grave» (art. 13.4). El art. 15 declara punibles el delito consumado y la tentativa, categoría ésta que unifica todas las formas imperfectas de ejecución, (art. 16) desapareciendo la frustración y señalando para los autores de tentativa «la pena inferior en uno o dos grados a la señalada por la ley para el delito consumado en la extensión que se estime adecuada, atendiendo al peligro inherente al intento y al grado de ejecución alcanzado» (art. 62) ${ }^{11}$; consecuentemente, «las faltas solo se castigarán cuando hayan sido consumadas, excepto las intentadas contra las personas o el patrimonio». Se hace una regulación específica de los efectos del desistimiento y arrepentimiento penalmente relevantes, siguiendo la jurisprudencia, colmando una tradicional laguna del ordenamiento penal (art. 16.2 y 3 ).

9 Cfr. GARCÍA PABLOS DE MOLINA, A., «Proyecto de Código Penal de 1992: Parte General (Teoría Jurídica del Delito)», en La Reforma del Código Penal. Edit. Icade. ob. cit., pág. 61 y ss.; CEREZO MIR, J., en Curso de Derecho Penal Español, PG. I. Introducción. 5ª edic., Editorial Tecnos. Madrid, 1996, pág. 138.

10 Son supuestos de crimena culposa, entre otros: los de homicidio (art. 142), aborto (146); lesiones (152); lesiones al feto (158); sustitución de un niño por otro (220.5); daños (267 y 324); blanqueo de capitales (301.3); medio ambiente (331); energía nuclear (344); estragos (347); incendios (358); salud pública (367); falsedad documental (391); prevaricación judicial (447); deslealtad profesional (467.2, p. $2^{\circ}$ ); prevaricación de abogado o procurador $\left(467\right.$, p. $3^{\circ}$ ); faltas de lesiones y de muerte (621). No obstante, esta fórmula puede producir, a veces efectos perniciosos, por la técnica punitiva del error de tipo vencible (art. 14). Cfr. LÓPEZ BARJA DE QUIROGA, J., «El delito imprudente en el Código Penal de 1995», en RPJ (Revista del Poder Judicial), no 40, octubre-diciembre 1995, Separata, CGPJ., págs. 219; SÁNCHEZ TOMAS, JM., «La problemática del error sobre los elementos que agravan al pena a través del ejemplo del error sobre la edad de los doce años», en ADPCP (Anuario de Derecho Penal y Ciencias Penales), 1993.

11 Excepcionalmente, la tentativa en el supuesto de delitos contra la corona previstos en el art. 485 CP. tiene una regulación específica y tratamiento punitivo que se aparta de las reglas generales, permitiendo rebajar la pena tan solo en un grado (art. 485.2). 
En cuanto a las causas que eximen de responsabilidad criminal (Cap. II, Tit. Primero), resulta novedosa la elevación de la mayoría de edad penal a los 18 años. Si bien, cuando el menor «de dicha edad cometa un hecho delictivo podrá ser responsable con arreglo a lo dispuesto en la ley que regule la responsabilidad penal del menor» (art. 19). En coherencia con el moderno criterio mantenido por la doctrina y jurisprudencia de que la imputabilidad requiere capacidad de comprender y valorar la ilicitud del hecho y de actuar conforme a dicho entendimiento ${ }^{12}$, el Código Penal declara exento de responsabilidad criminal «el que al tiempo de cometer la infracción penal, a causa de cualquier anomalía o alteración psíquica, no pueda comprender la ilicitud del hecho o actuar conforme a esa comprensión» (art. 20.1ํㅜ); el párrafo segundo de este mismo artículo, acude al expediente de las acciones liberae in causa para establecer la delimitación del trastorno mental transitorio, que no eximirá de pena «cuando hubiese sido provocado por el sujeto con el propósito de cometer el delito o hubiera previsto o debido prever su comisión». El núm. 2 de este mismo artículo extiende la exención de responsabilidad criminal sirviéndose del mismo expediente «el que al tiempo de cometer la infracción penal se halle en estado de intoxicación plena por el consumo de bebidas alcohólicas, drogas tóxicas, estupefacientes, sustancias psicotrópicas u otras que produzcan efectos análogos, siempre que no haya sido buscado con el propósito de cometerla o no se hubiese previsto o debido prever su comisión, o se halle bajo la influencia de un síndrome de abstinencia, a causa de su dependencia de tales sustancias, que le impida comprender la ilicitud del hecho o actuar conforme a esa comprensión». Por lo demás, el catálogo de eximentes no se altera significativamente, manteniéndose la eximente de alteración grave de la conciencia de la realidad derivada de problemas sensoriales y de percepción (art. 20.3ํ); legítima defensa, si bien se añade al primero de los requisitos (Agresión ilegítima), en caso de defensa de bienes, el ataque a los mismos que constituya no sólo delito, sino también falta «y los ponga en grave peligro de deterioro o pérdida inminentes» (art. 20.4을 ; el estado de necesidad no resulta alterado, no así el miedo insuperable que suprime la exigencia relativa a la entidad de dicho miedo (art. 20.6ㅇ). Se mantiene la redacción de obrar «en cumplimiento de un deber o en el ejercicio legítimo de un derecho, oficio o cargo» (art. 20.7을. Se añade en el párrafo segundo del núm. 7 del art. 20, que en los supuestos de los tres primeros números de este artículo se apliquen, en su caso, «las medidas de seguridad previstas en este Código». Finalmente se suprimen, como eximentes, la fuerza irresistible, y obediencia debida.

Respecto de las circunstancias que atenúan la responsabilidad criminal (Cap. III, Tit. Primero) se advierten, algunas modificaciones, como la de actuar el culpable a causa de su grave adicción a las sustancias mencionadas en el núm. 2 del art. 20, manteniendo la tradicional de «arrebato, obcecación u otro estado pasional de entidad semejante» (art. 21.3르), modifica la de arrepentimiento al admitir la relevancia de éste cuando se manifieste por el culpable «antes de conocer que el

12 Cfr. RODRÍGUEZ DEVESA, JMª./SERRANO GÓMEZ, A., en Derecho Penal Español, PG., ob. cit., págs. 447 y ss.; MIR PUIG, S., en Derecho Penal. PG., $4^{\text {a }}$ edic., corregida y puesta al día con arreglo al Código Penal de 1995, Edit. PPU, S.A., Barcelona, 1996, págs. 571 y ss. 
procedimiento judicial se dirige contra él, a confesar la infracción a las autoridades» (art. 21.4 ${ }^{a}$ ). Novedad, sin duda, es la de haber procedido el culpable a reparar el daño ocasionado a la víctima, disminuir sus efectos, en cualquier momento del procedimiento y, desde luego, siempre que sea «con anterioridad a la celebración del acto del juicio oral» (art. 21.5 ). No se introducen otras modificaciones, manteniéndose la eximente incompleta (art. 20.1를, circunstancia analógica (art. 21.6ํ) y suprimiéndose la minoría de 18 años, embriaguez no habitual y, en coherencia con el principio de culpabilidad, la preterintencionalidad ${ }^{13}$.

El Capítulo IV del Título Primero, simplifica las circunstancias agravantes de la responsabilidad criminal (art. 22), conserva la tradicional de alevosía (art. 22.1a), ejecutar el hecho mediante precio, recompensa o promesa (art. 22.3 ${ }^{\text {a }}$ ), abuso de confianza (art. 22.6ํㅡㄹ , prevalerse del carácter público que tenga el culpable (art. $22.7^{\mathrm{a}}$ ), y reincidencia (art. $22.8^{\mathrm{a}}$ ), si bien con respecto a ésta última, se produce una restricción a la denominada reincidencia específica, requiriendo el Código, no sólo que el delito por el que previamente fue condenado ejecutoriamente el culpable se halla comprendido en el mismo Título del Código, sino que además «sea de la misma naturaleza»; en la de ensañamiento se da nueva redacción, añadiendo el término víctima (art. 22.5ํㅡㄹ. Se incorporan dos nuevas circunstancias agravantes de amplia dicción: la de "cometer el delito por motivos racistas, antisemitas u otra clase de discriminación referente a la ideología, religión o creencias de la víctima, la etnia, raza o nación a la que pertenezca, su sexo u orientación sexual, o la enfermedad o minusvalía que padezca» (art. 22.4를 ; y la de «ejecutar el hecho mediante disfraz, con abuso de superioridad o aprovechando las circunstancias del lugar, tiempo o auxilio de otras personas que debiliten la defensa del ofendido o faciliten la impunidad del delincuente» (art. 22.2 $2^{a}$ ). Las demás circunstancias que contemplaba el anterior Código desaparecen ${ }^{14}$. El Capítulo $\mathrm{V}$ y VI presentan algunas particularidades. El primero, referente a la circunstancia mixta de parentesco mantiene casi literalmente la dicción, suprimiendo la palabra «permanente» por la de «estable» (art. 23). El segundo, relativo a «Disposiciones generales» mantiene el concepto penal de autoridad, extendiéndolo a los órganos colegiados y a los

13 Este acertado criterio, conforme con la doctrina jurisprudencial, del que es claro exponente la Sentencia de 28 de marzo de 1984, que cierra el paso a la apreciación de esta circunstancia atenuante, prevista en el anterior Código Penal (art. 9.4 a TR. 1973), en los supuestos de «preterintencionalidad heterogénea». Cfr. GARCÍA PABLOS DE MOLINA, A., «Proyecto de Código Penal de 1992 ...», en La Reforma del Código Penal, ob. cit., pág. 66; CEREZO MIR, J., en Curso de Derecho Penal Español, PG., ob. cit., pág. 137.

14 Se suprime la circunstancia de premeditación; astucia, fraude o disfraz; cometer el delito con ocasión de incendio, naufragio u otra calamidad o desgracia; ejecutar el hecho con ofensa de la autoridad o desprecio del respeto que por la dignidad o edad mereciese el ofendido, o en su morada cuando no haya provocado el suceso; ejecutarlo por medio de inundación, incendio, veneno, explosión, destrucción de aeronave, inundación o varamiento de nave, avería causada de propósito, descarrilamiento de locomotora, o el uso de otro artificio ocasionado a grandes estragos; realizar el delito por medio de la imprenta, radiodifusión u otro que facilite la publicidad. Con respecto a la circunstancia desaparecida de premeditación manifiesta la doctrina el desacierto que esto supone, pues debería ser considerada como una circunstancia de apreciación facultativa de acuerdo con la llamada teoría sintomática, cuando revele una mayor gravedad de la culpabilidad, debiendo limitarse su aplicación estrictamente a delitos contra las personas, al igual que la alevosía. Vid. CEREZO MIR, J., en Curso de Derecho Penal Español. PG., ob. cit., pág. 139. 
miembros "del Congreso de los Diputados, del Senado, de las Asambleas legislativas de las Comunidades Autónomas y del Parlamento Europeo». Reputa también autoridad a los funcionarios del Ministerio Fiscal, sustituye, con indudable buen criterio, el término individuos a que hacía referencia el anterior Código por el de funcionarios actual (art. 24). El concepto de funcionario público no experimenta modificación, si se introducen dos nuevos conceptos, a efectos penales, el de incapaz (inspirado en el art. 200 CC.) y el de documento (arts. 25 y 26).

El Título II del Libro Primero, bajo la rúbrica «De las personas criminalmente responsables de los delitos y faltas», dedica cinco artículos a la autoría, participación y actuación en nombre y representación de otro. El art. 27 declara responsables criminalmente a los autores y a los cómplices. Se suprime el encubrimiento como forma de participación impropia, elevándose a la categoría de delito autónomo, con emplazamiento sistemático entre los delitos contra la administración de justicia (Cap. III, Tít. XX, Lib. II) o contra el patrimonio (Cap. XIV, Tít. XIII, Lib. II). El art. 28 hace mención expresa a la autoría mediata, considerando también autores, los inductores y cooperadores necesarios; la complicidad no se ve alterada (art. 29); si lo es el régimen de autoría y participación del art. 30 relativo a los delitos y faltas cometidos «utilizando medios o soportes de difusión mecánicos» que «no responderán criminalmente ni los cómplices ni quienes los hubieren favorecido personal 0 realmente", en cambio para los autores se establece un sistema de responsabilidad en cascada "de forma escalonada, excluyente y subsidiaria» y de acuerdo con un determinado orden (art. 30), ampliando el ámbito de aplicación de esta particular técnica, al declarar la posibilidad de dirigirse al responsable penal subsidiario "cuando por cualquier motivo distinto de la extinción de la responsabilidad penal, incluso la declaración de rebeldía o la residencia fuera de España, no pueda perseguirse a ninguna de las personas comprendidas en alguno de los números del apartado anterior».

El art. 31 regula la responsabilidad penal de las personas jurídicas con escasas diferencias cualitativas respecto al anterior Código Penal. Ahora se refiere al «que actúe como administrador de hecho o de derecho de una persona jurídica o en nombre o representación legal de otro...» frente a la anterior redacción que se refería al «que actuare como directivo u órgano de la persona jurídica...».

En cuanto al sistema de penas (Título III, Libro primero) las novedades más significativas son las siguientes: el Código se adscribe al sistema dualista (de penas y medidas) con un propósito fundamental que es el de alcanzar, en lo posible, los objetivos de resocialización que la Constitución le asigna. El sistema simplifica la regulación de las penas privativas de libertad, ampliando las posibilidades de sustituirlas por otras que afecten a bienes jurídicos menos básicos, por otro lado introduce cambios en las penas pecuniarias adoptando el sistema escandinavo de días-multa e incorporando los trabajos en beneficio de la comunidad ${ }^{15}$. El Código clasifica las penas con arreglo a su naturaleza, en privativas de libertad, privativas de otros derechos y multa (art. 32), y con arreglo a la gravedad, en penas graves,

15 Vid. Exposición de Motivos, LO. 10/1995, de 23 de noviembre, el Código Penal. 
menos graves y leves (art. 33) ${ }^{16}$. Son penas privativas de libertad: la prisión, el arresto de fin de semana y la responsabilidad civil subsidiaria por impago de multa (art. 35). La duración mínima de la pena de prisión es de seis meses y la máxima de veinte años «salvo lo que excepcionalmente dispongan otros preceptos del presente Código» (art. 36) ${ }^{17}$. Siendo posible la sustitución de las penas de prisión inferiores a un año por las de arresto de fin de semana o multa (art. 88.1) y excepcionalmente, las penas de prisión que no excedan de dos años, en determinados casos (art. 88.1. pár. segundo). «El arresto de fin de semana tendrá una duración de treinta y seis horas y equivaldrá, en cualquier caso, a dos días de privación de libertad» (art. 37). De entre las penas privativas de derechos, además de la inhabilitación, suspensión, privación del derecho de conducir, tenencia y porte de armas, y de residir en determinados lugares, se añaden los trabajos en beneficio de la comunidad (art. 39.g), éstos últimos, de acuerdo con la Constitución, no pueden imponerse sin el consentimiento del penado, obligándole a prestar su cooperación no retribuida en actividades de utilidad pública, ajustándose a las condiciones señaladas en el art. 49. Novedoso resulta la pena de días-multa (arts. 50 y ss.), este sistema supone la determinación de cuotas diarias con una extensión mínima que será de cinco días y máxima de dos años, la cuota mínima será de doscientas pesetas y la máxima de cincuenta mil, teniendo en cuenta para su fijación «exclusivamente la situación económica del reo, deducida de su patrimonio, ingresos, obligaciones y cargas familiares y demás circunstancias personales del mismo» (art. 50.5). En la Sentencia se determinará el tiempo y forma de pago de las cuotas, caso en que se divida en plazos (art. 50.6); pudiéndose reducir el importe de las cuotas, en caso de que el penado empeorare de fortuna (art. 51). Y si el condenado no satisficiere voluntariamente o por vía de apremio, la multa impuesta, quedará sujeto a responsabilidad personal subsidiaria de un día de privación de libertad por cada dos cuotas diarias no satisfechas (art. 53), dicha responsabilidad personal se podrá cumplir en régimen de arrestos de fin de semana (art. 53.1), incluso, previa conformidad del penado, el juez o tribunal podrá acordar que la responsabilidad subsidiaria se cumpla mediante trabajos en beneficio de la comunidad (art. 53.1.pár. segundo). Se contempla el abono en su totalidad del tiempo de privación de libertad sufrido en prisión preventiva y el de privación de derechos (art. 58) y como novedad la suspensión de la ejecución de la pena privativa de libertad (art. 80) dentro de los requisitos del art. 81; finalmente, con escasas variaciones se mantiene el régimen de libertad condicional (arts. 90 y ss.) y se da un concepto de habitualidad limitado al régimen general y especial de aplicación de las penas (art. 94).

16 No reputando penas, la detención, prisión preventiva y demás medidas cautelares de naturaleza penal; las multas y demás correcciones disciplinarias, se impongan a los subordinados o administrados, ni las privaciones de derechos y sanciones reparadoras que establezcan las leyes civiles o administrativas (art. 34).

17 De acuerdo con las reglas generales y especiales para la aplicación de las penas previstas en el Capítulo II del presente Título III, la duración de estas penas, en determinados casos, pueden llegar a ser de veinticinco y hasta treinta años de prisión (por ejemplo, art. 70.2.1 ${ }^{\circ}$, art. 76); con carácter específico y en este orden, arts. 139 y 140, para el asesinato; art. 485, delitos contra la corona; art. 571 y ss, delitos de terrorismo, entre otros. 
El Título IV del Libro I, va referido a las medidas de seguridad, compuesto por un total de catorce artículos, distribuidos en dos Capítulos. Lo más novedoso de esta regulación es la supresión de las medidas de seguridad predelictuales, de acuerdo con el criterio mantenido por la doctrina y Jurisprudencia ${ }^{18}$. Se deroga la Ley de peligrosidad y rehabilitación social, con sus modificaciones posteriores y disposiciones complementarias ${ }^{19}$. La aplicación de las medidas de seguridad exige, además, de los informes previos que el Juez o Tribunal estime conveniente, las

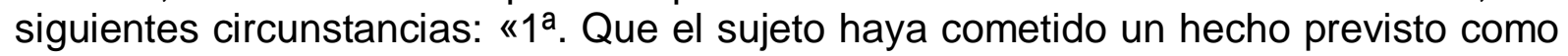
delito» y «2 ${ }^{a}$. Que del hecho y de las circunstancias personales del hecho pueda deducirse un pronóstico de comportamiento futuro que revele la probabilidad de comisión de nuevos delitos». Las medidas de seguridad pueden ser privativas (arts. 96 ss.) y no privativas de libertad (arts. 101 ss.) ${ }^{20}$. De acuerdo con el principio de mínima intervención, manifestando a través del sistema vicarial «las medidas de seguridad no pueden resultar ni más gravosas ni de mayor duración que la pena abstractamente aplicable al hecho cometido, ni exceder el límite de lo necesario para prevenir la peligrosidad del autor» (art. 6.2) ${ }^{21}$. Problema que queda sin resolver es la falta de previsión legislativa de medidas de seguridad postdelictuales aplicables a delincuentes habituales, peligrosos y reincidentes ${ }^{22}$.

El Título V del Libro I: «De la responsabilidad civil derivada de los delitos y faltas y de las costas procesales», contempla escasas novedades. Para determinar la

18 Cfr. BUENO ARUS, F., «El sistema de penas en el Proyecto de Código Penal español de 1992», en $L a$ Reforma del Código Penal, Revista ICADE, núm. 29, Madrid, 1993, págs. 87 y ss.; GARCÍA PABLOS DE MOLINA, A., en Proyecto de Código Penal de 1992. PG., ob. cit., págs. 70 y 71; y en Derecho Penal. Introducción, Editorial Servicio de Publicaciones. Facultad de Derecho. UCM., Madrid, 1995, págs. 221 y ss.; CEREZO MIR, J., en Curso de Derecho Penal Español, ob. cit., pág. 141; GARCÍA ARAN, M., «Medidas de internamiento», Separata. En Estudios sobre el Código Penal de 1995 (Parte General), Estudios de Derecho Judicial. Escuela Judicial. Consejo General del Poder Judicial, págs. 402 y ss.; Vid. SS. TC. $n^{\circ} 23,14$ febrero 1986 y nº 21/1987.

19 Vid. Disp. Derog. Unica, apartado c) de la LO. de 23 de noviembre de 1995, del Código Penal, por la que se deroga la Ley 16/1970, de 4 de agosto, sobre peligrosidad y rehabilitación social.

20 De entre las primeras, se encuentran el internamiento en centro psiquiátrico, de deshabituación y educativo especial; de entre las segundas, la prohibición de estancia y residencia en determinados lugares, privación del derecho a conducir de vehículos a motor y ciclomotores, de licencia o del permiso de armas; inhabilitación profesional; expulsión del territorio nacional de extranjeros no residentes legalmente en España; y las demás previstas en el art. 105 del CP. (art. 96).

21 El precedente inmediato de este sistema lo encontramos en el párrafo segundo del artículo 9.1 del Código Penal anterior de 1973, modificado por la LO. de 25 de junio de 1973, sobre reforma parcial y urgente del Código Penal.

22 Esta falta de previsión, de indiscutible importancia, es denunciada por la doctrina. Vid. CEREZO MIR, J., en Curso de Derecho Penal Español, ob. cit., pág. 141; GARCÍA PABLOS DE MOLINA, A., en Derecho Penal. Introducción, ob. cit., págs. 220 y ss.; GARCÍA ARAN, M., Medidas de internamiento, Separata. ob. cit., pág. 413. 
responsabilidad civil y su extensión, se prescinde de declaraciones genéricas o programáticas, previniendo el art. 109 que «la ejecución de un hecho descrito por la ley, como delito o falta obliga a reparar, en los términos previstos en las Leyes, los daños y perjuicios por él causados». Mantiene el contenido de la responsabilidad civil, a la restitución, reparación del daño e indemnización de perjuicios materiales y morales (art. 110). Dentro de las personas civilmente responsables se extiende, por un lado, a «los aseguradores que hubieren asumido el riesgo de las responsabilidades pecuniarias derivadas del uso o explotación de cualquier bien, empresa, industria o actividad cuando, como consecuencia de un hecho previsto en este Código, se produzca el evento que determine el riesgo asegurado, serán responsables civiles ... hasta el límite de la indemnización legalmente establecida 0 convencionalmente pactada, sin perjuicio del derecho de repetición...» (art. 117). Y por otro, al «Estado, la Comunidad Autónoma, la provincia, la isla, el municipio y demás entes públicos, según los casos, responden subsidiariamente de los daños causados por los penalmente responsables de los delitos dolosos y culposos, cuando éstos sean autoridad, agentes, y contratados de la misma o funcionarios públicos en el ejercicio de sus cargos o funciones siempre que la lesión sea consecuencia directa del funcionamiento de los servicios públicos que les estuvieren confiados...» (art. 121). Obsérvese que en estos supuestos del art. 121 sólo se responde por delitos, no por faltas., lo que no deja de ser paradójico e insólito para un Estado social de derecho, como proclama la Constitución Española (arts. 1 y 106).

De nuevo cuño, son sin embargo alguna de las consecuencias accesorias que contempla el Título VI. Por un lado, se mantiene y mejora la redacción del comiso (arts. 127 y 128); por otro se incorporan nuevas consecuencias aplicables a personas jurídicas y empresas (art. 129) ${ }^{23}$. Estas consecuencias son de naturaleza y régimen sui generis ${ }^{24}$ cuyo fundamento está orientado «a prevenir la continuidad en la actividad delictiva y los efectos de la misma» (art. 129.3).

El Título VII del Libro Primero, «De la extinción de la responsabilidad criminal y sus efectos», concluye la parte general del Código Penal, presenta escasísimas novedades dignas de mención. El Capítulo I, referente a las «causas que extinguen la responsabilidad criminal» suprime, de acuerdo con la Constitución, la amnistía (art. 130), adaptándose los tiempos de prescripción al nuevo sistema de penas (arts. 131 ss.) y medidas (art. 135). El Capítulo II, se refiere a la cancelación de antecedentes delictivos (art. 136), incluyendo ahora la anotación y cancelación de las medidas de seguridad (art. 137).

El Libro II del Código Penal («Delitos y sus penas») destaca por el nuevo orden sistemático que adopta. Los diferentes delitos se estructuran en función de su gravedad, del bien jurídico protegido ${ }^{25}$. El Código de 1995 comienza con la

23 Cfr. $§ 73$ a 76.a. StGB.

24 Vid. GARCÍA PABLOS DE MOLINA, A., en Derecho Penal. Introducción, ob. cit., pág. 69.

25 Se aparta el vigente Código de la anterior sistemática del TR. de 1973, heredada, sin duda, del vetusto Código Penal de 1848 donde el legislador mantenía una tradicional preocupación por la protección del Estado, comenzando ha regular, en primer término, los delitos que atentaban contra la seguridad de éste. Por tanto, la sistemática del Libro II del Código queda así: Título I: Del homicidio y sus formas; Título II: Del aborto; Título III: De las lesiones; Título IV: De las lesiones al feto; Título V: Delitos relativos a la 
protección del bien jurídico de mayor valor, como es la vida humana independiente, dependiente, seguido de la integridad, libertad, etc. para concluir con los delitos contra el Estado y comunidad internacional. El propósito del legislador es afrontar y dar respuesta, de acuerdo con el principio de mínima intervención, intervención fragmentaria, como exigencia político criminal, a los problemas que una sociedad moderna y cada vez más compleja demanda ${ }^{26}$. De acuerdo con el sentir del legislador, las novedades más significativas del Libro II del Código Penal son las siguientes: respecto del homicidio y sus formas, en coherencia con la rúbrica del Título I, regula, en primer término, el género (homicidio) seguido de otras formas de homicidio (asesinato, etc.). En el asesinato las circunstancias se limitan a tres: alevosía, precio, recompensa o promesa y ensañamiento (art. 139) ${ }^{27}$. Hay una despenalización parcial de la eutanasia (art. 143.4). El delito de aborto mantiene su regulación, si bien para los supuestos de despenalización se acude al vigente art. 417 bis del Código Penal, TR. de $1973^{28}$. Se mejora la técnica en la regulación del delito de lesiones (art. 147 y ss.), eliminando elementos normativos incompatibles con el principio de legalidad, ganándose en seguridad jurídica. Mínima es la diferencia en la regulación de la eficacia del consentimiento en las lesiones (arts. 155 y 156). Novedoso es la regulación de las lesiones al feto (arts. 157 y 158); delitos relativos a la manipulación genética (arts. 159 a 162); integridad moral (arts. 173 a 177); omisión del deber de socorro, en particular, del profesional sanitario (arts. 195 y 196); delitos contra la intimidad, derecho a la propia imagen e inviolabilidad del domicilio (arts. 197 a 204). En los delitos contra el honor, se sustituyen los tradicionales conceptos de injurias y calumnias (arts. 205 y 208). Se

manipulación genética; Título VI: Delitos contra la libertad; Título VII: De las torturas y otros delitos contra la integridad moral; Título VIII: Delitos contra la libertad e indemnidad sexuales; Título IX: De la omisión del deber de socorro; Título X: Delitos contra la intimidad, el derecho a la propia imagen y la inviolabilidad del domicilio; Título XI: Delitos contra el honor; Título XII: Delitos contra las relaciones familiares; Título XIII: Delitos contra el patrimonio y contra el orden socioeconómico; Título XIV: De los delitos contra la Hacienda Pública y contra la Seguridad Social; Título XV: Delitos contra los derechos de los trabajadores; Título XVI: De los delitos relativos a la ordenación del territorio y la protección del patrimonio histórico y del medio ambiente; Título XVII: De los delitos contra la seguridad colectiva; Título XVIII: De las falsedades; Título XIX: Delitos contra la Administración pública; Título XX: Delitos contra la Administración de Justicia; Título XXI: Delitos contra la Constitución; Título XXII: Delitos contra el orden público; Título XXIII: De los delitos de traición y contra la paz y la independencia del Estado y relativos a la defensa nacional; Título XXIV: Delitos contra la Comunidad Internacional. Téngase en cuenta que las reformas posteriores de las que trataremos más adelante, han añadido nuevos Títulos al Código, como el Título XV BIS: Delitos contra los derechos de los ciudadanos extranjeros y Título XIX BIS: De los delitos de corrupción en las transacciones comerciales internacionales.

26 Cfr. Exposición de Motivos, LO. 10/1995, de 23 de noviembre, del Código Penal.

27 Se suprime el resto de circunstancias, como la premeditación, la inundación, el incendio, el veneno o el explosivo; así como los delitos de parricidio e infanticidio, figuras éstas de fuerte arraigambre y larga tradición en nuestro ordenamiento jurídico penal español. Cfr. CEREZO MIR, J., en Curso de Derecho Penal Español, ob. cit., pág. 143.

28 Vid. Disposición derogatoria única, LO: 10/1995, de 23 de noviembre, apartado 1.a). 
potencia la protección de bienes jurídicos en el seno familiar (arts. 217 a 222), y los derechos y deberes familiares (arts. 223 a 233). De nuevo cuño son los delitos contra el orden socioeconómico, que los incluye el legislador, junto con los del patrimonio en el mismo Título XIII. En orden, a los patrimoniales se mantienen las clásicas figuras ya conocidas hurto, robo, estafa, si bien para ésta última se añaden las cometidas «valiéndose de alguna manipulación informática o artificio semejante consigan la transferencia no consentida de cualquier activo patrimonial en perjuicio de tercero» (art. 248.2), como particularidades destacan la nueva denominación para el «robo y hurto de uso de vehículos», en sustitución de la anterior denominación utilización ilegítima de vehículo de motor ajeno. Como modalidad de usurpación de inmueble, se incorpora la figura de los okupas (art. 245.2) ${ }^{29}$. En el Capítulo de las insolvencias punibles (VI), se incluye la suspensión de pagos en el ya amplio catálogo de delitos que contempla esta parte del Código (art. 260), otro tanto ocurre con el alzamiento de bienes para eludir responsabilidades civiles (art. 258), o para favorecer a ciertos acreedores (art. 259) ${ }^{30}$. En el Capítulo de los daños se mantienen éstos con carácter residual, el legislador sigue sin dar un concepto penal de daños (art. 263) ${ }^{31}$; introduce los daños a «datos, programas o documentos electrónicos ajenos contenidos en redes, soportes o sistemas informáticos» (art. 264.2); e incluye los daños militares dentro de los patrimoniales y no dentro de los relativos a la defensa nacional (Tit. XXIII). El tratamiento penal de los daños imprudentes es de nuevo cuño, señalando ahora tres requisitos: primero que se hayan causado por imprudencia grave, segundo que la cuantía de éstos supere los diez millones de pesetas y tercero que medie denuncia de la persona agraviada o representante legal de ésta (art. 267); mantiene la excusa absolutoria en delitos patrimoniales pero limitándola únicamente «a los cónyuges que no estuvieren separados legalmente o de hecho o en proceso judicial de separación, divorcio o nulidad de su matrimonio y los ascendientes, descendientes y hermanos por naturaleza o adopción, así como los afines en primer grado si viviesen juntos ...», no aplicándose «Esta disposición» «a los extraños que participaren en el delito» (art. 268). Se le da nueva regulación a

29 En mi opinión, este delito debería desaparecer de acuerdo con el principio de ultima ratio, intervención subsidiaria del Derecho Penal, estos eventuales problemas deben ser resueltos por vía administrativa y no penal.

30 El alzamiento de bienes, con carácter general, ya está previsto en el art. 257, por lo que es innecesario el art. 258. Todas estas conductas deberían ser objeto de revisión por el legislador y tener respuesta en la mayoría de los casos, a través del Derecho civil, mercantil o administrativo. Incluir la suspensión de pagos, como eventual conducta delictiva, supone una intervención máxima del Derecho penal, incompatible con la finalidad que se persiguen en situaciones de crisis de las empresas, que es llegar a un acuerdo con los acreedores; ésta y no otra, es la finalidad que se pretende conseguir con la suspensión de pagos a través del convenio. Si me parece acertado, castigar los delitos de quiebra y concurso fraudulento y la no vinculación al Juez penal de la previa calificación de la insolvencia por el Juez civil, pues supone una mayor agilidad en la administración de justicia (art. 260.4). Por otra parte, la Ley de suspensión de pagos, de 26 de julio de 1922, se creó ad hoc y con carácter provisional para resolver la quiebra del Banco de Barcelona, lo cierto es que todavía está vigente, debería, en su caso, de modificarse ésta y dar respuesta civil a los eventuales problemas que puedan surgir para afianzar un déficit determinado, nivelando los balances contables.

31 No tiene en cuenta las opiniones de la doctrina. Vid. SERRANO BUTRAGUEÑO, IJ., Los delitos de daños. Edit. Aranzadi, Pamplona, 1994. 
los delitos contra la propiedad intelectual e industrial, mercado y consumidores (arts. 270 a 288), y nuevo emplazamiento sistemático a los daños en cosa propia de utilidad social, al cual se dedica un solo Capítulo (XII, art. 289). Pero lo más novedoso es, sin duda, la regulación de los delitos societarios. Se trata de hacer frente a ciertas formas de criminalidad patrimonial no convencional. Hasta la fecha estos comportamientos se desviaban a los tipos generales, como la estafa, apropiación indebida, falsedades, prevaricación, cohecho. No obstante, la preocupación del legislador por castigar estas conductas resulta insólito y solo explicable por el principio de ultima ratio de que no se persigan de oficio, salvo los supuestos de delito masa o que afecte a intereses generales (art. 296). Se potencia la receptación en relación con los delitos societarios, así como las conductas que consistan en blanquear dinero de procedencia ilícita (arts. 298 a 304). Los delitos contra la Hacienda Pública y contra la Seguridad Social se mantienen intactos a los del anterior Código Penal ${ }^{32}$. Se mejora la protección del derecho de los trabajadores, de acuerdo con la problemática migratoria y riesgos laborales (arts. 311 a 318). De nuevo cuño, son también, los delitos relativos a la ordenación del territorio (arts. 319 y 320), protección del patrimonio (arts. 321 a 324) y del medio ambiente (arts. 325 a 331). Exagerada es, en mi opinión, la protección dispensada a la flora y fauna (arts. 332 a 337). Otras novedades son relacionadas con la seguridad del tráfico, incorporándose la conducta consistente en negarse a someterse a pruebas de alcoholemia (art. 380). En materia de delitos contra la Administración pública, destaca la supresión del delito de prevaricación imprudente cometido por funcionario público. Como delitos contra la Administración de justicia encontramos el encubrimiento como delito autónomo (arts. 451 a 454); obstrucción a la justicia y deslealtad profesional (arts. 463 a 467). Dentro de los delitos contra la Comunidad Internacional (Tít. XIV), dedica el Cap. III a los delitos contra las personas y bienes protegidos en caso de conflicto armado (arts. 608 a 614).

En lo referente al Libro III (Faltas y sus penas) se produce un fuerte recorte con respecto a la legislación derogada. No obstante, la estructura respeta los modelos anteriores $^{33}$. Como particularidades más significativas, destaca dentro de las faltas contra las personas (art. 621), la de homicidio por imprudencia leve y necesidad de denuncia de la persona agraviada para perseguir éstas, de acuerdo con el principio de mínima intervención (art. 621.6). En cuanto a las patrimoniales, valiéndose del mismo principio, suprime la de daños imprudentes; la divisoria se fija en un máximo de cincuenta mil pesetas. Finalmente, en materia de penas, se imponen de acuerdo con el sistema tripartito, únicamente las leves (arts. 13.3 y 33.4). Mantiene el tradicional arbitrio judicial, sin sujeción a las reglas previstas en el Libro I (arts. 61 a 72). De acuerdo con el principio de mínima intervención, las faltas perseguibles mediante denuncia de la persona agraviada o representante legal, el perdón del

32 Se introdujeron al anterior Código por LO. 6/1995, de 29 de mayo, sobre delitos contra la Hacienda Pública y Seguridad Social.

33 Título I: Faltas contra las personas; Título II: Faltas contra el patrimonio; Título III: Faltas contra los intereses generales; Título IV: Faltas contra el orden público; Título V: Disposiciones comunes a las faltas. 
ofendido o su representante extinguirá la acción penal o la pena. Cuando la denuncia sea del Ministerio Público, por tratarse de menores, incapaces o persona desvalida, el Fiscal podrá rechazar el perdón conforme al párrafo segundo del $n \div 4$ del art. 130 (art. 639) $^{34}$.

El propósito del legislador, con la elaboración de este Código Penal no es pretender «haber realizado una obra perfecta, sino, simplemente, una obra útil» ${ }^{35}$.

\section{Bibliografía}

ANTÓN ONECA, J., en Derecho Penal, $2^{\underline{a}}$ edic., anotada y puesta al día por José Julián Hernández Guijarro y Luis Beneytez Merino, Edit. Akal, Madrid, 1986.

BUENO ARUS, F., Los antecedentes penales, Boletín de Información del Ministerio de Justicia, núm. 929, 15 octubre 1972; Los aspectos criminógenos de la ley penal, Revista La Ley, núm. 851, 13 enero 1984; Derecho penal y Estado democrático en España, Revista ICADE, núm. 10, Madrid, 1987; «El sistema de penas en el Proyecto de Código Penal español de 1992», en La Reforma del Código Penal, Revista ICADE, núm. 29, Madrid, 1993; Delito, seguridad ciudadana y abolicionismo, Revista ICADE, núm. 31, Madrid, 1994; La teoría de la Ley penal en el proyecto de Código Penal Español de 26 de septiembre de 1994, en Actualidad Penal, no 16, Madrid, 1995.

CEREZO MIR, J., en Curso de Derecho Penal Español. PG. I. Introducción. 5a edic., Editorial Tecnos. Madrid, 1996.

GARCÍA ARAN, M., "Medidas de internamiento», Separata. En Estudios sobre el Código Penal de 1995 (Parte General), Estudios de Derecho Judicial. Escuela Judicial. Consejo General del Poder Judicial.

GARCÍA PABLOS DE MOLINA, A., «Proyecto de Código Penal de 1992. Parte General (Teoría jurídica del delito)», en La Reforma del Código Penal, Revista ICADE, Madrid, 1993, núm. 29; en Derecho Penal. Introducción, 1aㅡ edic., Editorial Servicio de Publicaciones. Facultad de Derecho. UCM., Madrid, 1995.

GIMBERNAT ORDEIG, E., «Prólogo a la segunda edición», en Código Penal, Edit. Tecnos, $2^{\mathrm{a}}$ edic., Madrid, 1996.

GRACIA MARTÍN, L., «Política criminal y dogmática jurídico penal del proceso de reforma penal en España», en Actualidad Penal no 17 y 18, 1994.

34 Entre otros, los comentarios que se han hecho al Código Penal de 1995 han sido los siguientes: QUINTERO OLIVARES, G./VALLE MUNIIZ, JM./VV.AA., en Comentarios a la Parte Especial del Derecho Penal, Edit. Aranzadi, Pamplona, 1996; VAZQUEZ IRUZUBIETA, C., en El nuevo Código Penal comentado (Ley 10/1995, de 23 de noviembre), Edit. Edersa, Madrid, 1996.

35 Vid. Exposición de Motivos de LO. 10/1995, de 23 de noviembre, del Código Penal. En la votación final del proyecto de ley, la intervención del Ministro del Interior, Sr. Belloch, ante el Pleno del Congreso de los Diputado, decía: «No se trataba de hacer una norma perfecta sino útil ... es (el nuevo Código) un conjunto de propuestas para afrontar con decisión los problemas penales que afronta España hoy en día». Desde una postura escéptica, la doctrina cree que solo el tiempo dirá si es así. 
LASSO GAITE, JF., en Crónica de la Codificación Española, 5, Codificación Penal, vol. I., Ministerio de Justicia, Secretaría General Técnica, Centro de Publicaciones, Madrid, 1970.

LÓPEZ BARJA DE QUIROGA, J., «El delito imprudente en el Código Penal de 1995», en RPJ (Revista del Poder Judicial), no 40, octubre-diciembre 1995, Separata, CGPJ.

LÓPEZ GARRIDO, D./GARCÍA ARAN, M., en El Código Penal de 1995 y la voluntad del legislador. Comentario al texto y al debate parlamentario. Madrid, 1996.

MANZANARES SAMANIEGO, JL., "Comentarios a la parte general del proyecto de Ley Orgánica del Código Penal», en Revista de Derecho Penal y Criminología, núm. 2, Madrid, 1992.

MIR PUIG, S., en Derecho Penal. PG., 4aㅡ edic., corregida y puesta al día con arreglo al Código Penal de 1995, Edit. PPU, S.A., Barcelona, 1996.

QUINTERO OLIVARES, G./VALLE MUÑIZ, JM./VV.AA., en Comentarios a la Parte Especial del Derecho Penal, Edit. Aranzadi, Pamplona, 1996.

RODRíGUEZ DEVESA, JMํạ./SERRANO GÓMEZ, A., en Derecho Penal Español PG., 18ª̣ edic., revisada y puesta al día. Edit. Dikynson, Madrid, 1995.

SÁNCHEZ TOMAS, JM., «La problemática del error sobre los elementos que agravan al pena a través del ejemplo del error sobre la edad de los doce años", en ADPCP (Anuario de Derecho Penal y Ciencias Penales), 1993.

SERRANO BUTRAGUEÑo, IJ., Los delitos de daños. Edit. Aranzadi, Pamplona, 1994.

SERRANO GÓMEZ, A., «El proyecto de Código Penal de 1994 y las previsiones del art. 88 de la Constitución», en Revista de Derecho Penal y Criminología, núm. 4, Madrid 1994.

VAZQUEZ IRUZUBIETA, C., en El nuevo Código Penal comentado (Ley 10/1995, de 23 de noviembre), Edit. Edersa, Madrid, 1996. 